\title{
Diagnosis and treatment of solid pseudopapillary tumor of the pancreas: experience of one single institution from Turkey
}

Ayşe Yagcı ${ }^{1 \dagger}$, Savas Yakan ${ }^{2 \dagger}$, Ali Coskun ${ }^{2 *}$, Nazif Erkan ${ }^{2}$, Mehmet Yıldııım², Evrim Yalcın ${ }^{1}$ and Hakan Postacı ${ }^{1}$

\begin{abstract}
Background: Solid pseudopapillary neoplasia (SPN) of the pancreas is an extremely rare epithelial tumor of low malignant potential. SPN accounts for less than $1 \%$ to $2 \%$ of exocrine pancreatic tumors. The aim of this study is to report our experience with SPN of the pancreas. It includes a summary of the current literature to provide a reference for the management of this rare clinical entity.
\end{abstract}

Methods: A retrospective analysis was performed of all patients diagnosed and treated for SPN in our hospital over the past 15 years (1998 to 2013). A database of the characteristics of these patients was developed, including age, gender, tumor location and size, treatment, and histopathological and immunohistochemical features.

Results: During this time period, 255 patients with pancreatic malignancy (which does not include ampulla vateri, distal choledocal and duodenal tumor) were admitted to our department, only 10 of whom were diagnosed as having SPN (2.5\%). Nine patients were women (90\%) and one patient was a man (10\%). Their median age was 38.8 years (range 18 to 71). The most common symptoms were abdominal pain and dullness. Seven patients (70\%) presented with abdominal pain or abdominal dullness and three patient (30\%) were asymptomatic with the diagnosis made by an incidental finding on routine examination. Abdominal computed tomography and/or magnetic resonance imaging showed the typical features of solid pseudopapillary neoplasm in six (60\%) of the patients. Four patients underwent distal pancreatectomy with splenectomy, one patient underwent a total mass excision, and one patient underwent total pancreatic resection. Two required extended distal pancreatectomy with splenectomy. Two underwent spleen-preserving distal pancreatectomy.

Conclusions: SPN is a rare neoplasm that primarily affects young women. The prognosis is favorable even in the presence of distant metastasis. Although surgical resection is generally curative, a close follow-up is advised in order to diagnose a local recurrence or distant metastasis and choose the proper therapeutic option for the patient.

Keywords: Solid pseudopapillary neoplasia, Diagnosis, Treatment

\section{Background}

Solid pseudopapillary neoplasia (SPN) of the pancreas is an extremely rare epithelial tumor of low malignant potential. SPN accounts for less than $1 \%$ to $2 \%$ of exocrine pancreatic tumors [1]. Until it was defined by the World Health Organization (WHO) in 1996 as 'solid pseudopapillary tumor' of the pancreas, this tumor was described by using various names including 'solid cystic tumor,', papillary cystic

\footnotetext{
* Correspondence: dralicoskun@hotmail.com

${ }^{\dagger}$ Equal contributors

${ }^{2}$ Department of Surgery, M.D, SB Izmir Bozyaka Education and Research Hospital, Izmir, Turkey

Full list of author information is available at the end of the article
}

tumor', 'papillary epithelial neoplasia, 'solid and papillary epithelial neoplasia,' 'papillary epithelial tumor' and 'Frantz's tumor', 'solid and papillary tumor', 'solid-cysticpapillary epithelial neoplasm, 'benign or malignant papillary tumor of the pancreas' [2]. These tumors typically occur in young women during the second to fourth decade of life and are histologically characterized by cystic areas and solid pseudopapillary arranged cells. The origin of these tumors is still a matter of controversy.

In this study, we report our experience with SPN of the pancreas and include a summary of the current literature to provide a reference for the management of this rare clinical entity. 


\section{Methods}

A retrospective analysis was carried out of all patients diagnosed and treated for SPN in our hospital over the past 15 years (1998 to 2013). A database of the characteristics of these patients was developed, including age, gender, tumor location (data were derived from radiological investigations or surgical records) and size (data were derived from radiological investigations or surgical records and finally confirmed by pathology), treatment (data were derived from the medical records, including the types of surgery), and histopathological and immunohistochemical features. Pre-operative fine needle aspiration cytology FNAC) was performed in one patient. All the patients who underwent resection were followed up every six months. The investigations performed included routine blood studies, chest X-ray, CA-19-9 level and either an ultrasound or computed tomography (CT) scan of the abdomen.

This study was approved by the Local Institutional Review Board of Izmir Bozyaka Education and research hospital.

\section{Results}

During this time period, of 255 patients with pancreatic malignancy (which does not include ampulla vateri, distal choledocal and duodenal tumor) admitted to our department, only 10 were diagnosed as having SPN (2.5\%). Nine patients were women (90\%) and one patient was a man (10\%). The patients had a median age of 38.8 years (range 18 to 71 ). The most common symptoms were abdominal pain and dullness. Seven patients (70\%) presented with abdominal pain or abdominal dullness and three patient (30\%) were asymptomatic with the diagnosis made by an incidental finding on routine examination. Abdominal CT and/or magnetic resonance imaging (MRI) showed the typical features of solid pseudopapillary neoplasm in six $(60 \%)$ of the patients (Figure 1). Tumor markers (AFP,

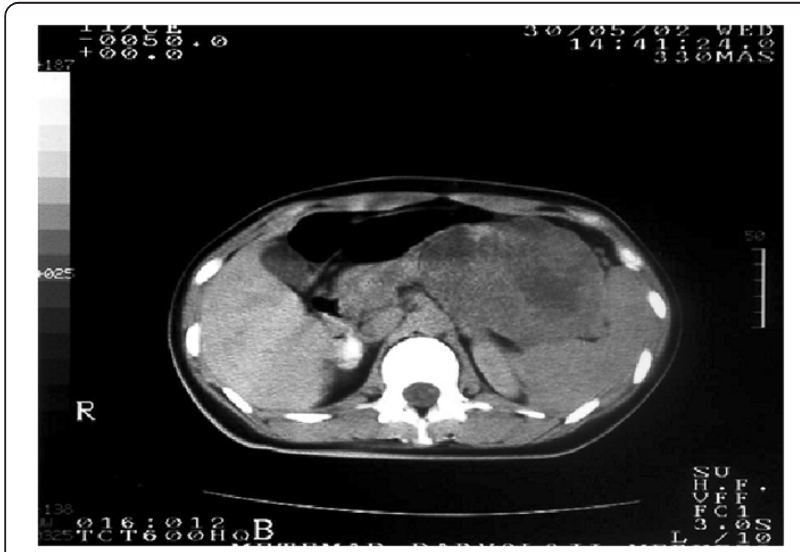

Figure 1 Magnetic resonance imaging shows that the tumor is a well-marginated, large, encapsulated, solid and cystic mass with areas of hemorrhagic degeneration, as revealed by high signal intensity.
CEA, CA 19-9 and CA 125) were normal preoperatively in all patients. Usually, the tumors appeared as wellcircumscribed lesions with a mixed cystic and solid component but were almost entirely solid or else cystic with thick walls. In one patient the tumor was located in the pancreatic head (10\%), in four patients in the body (40\%) and in the remaining five patients in the tail (50\%). Four patients underwent distal pancreatectomy with splenectomy, one patient underwent a total mass excision and one patient underwent total pancreatic resection. Two required extended distal pancreatectomy with splenectomy. Two underwent spleen-preserving distal pancreatectomy. The mean diameter of the tumor was $8 \mathrm{~cm}$ (range 3 to $13 \mathrm{~cm}$ ). Patient characteristics are summarized in Table 1.

In eight cases lymph node dissection was done in a number between 4 and 14 , whereas no dissection was needed for two patients. No lymph node metastasis was present in any patient. Macroscopically, there was diffuse hemorrhage and minimal necrosis between solid and cystic areas (Figure 2). At histopathological examination, tumor mass separated from pancreas with a fibrous capsula was seen. Pseudopapillary, cystic and solid growth patterns were seen in the tumor mass. Tumor cells had an ovally shaped, small and centrally localized nucleus and large eosinophilic cytoplasm. Tumors consisted of pseudopapillary structures made of cells aligned around fine vessels, solid areas, hemorrhagic areas and cystic areas of different size (Figure 3). No mitosis was seen in five cases, whereas minimal mitosis was present in two cases $(2 / 10$ per high powered field) and multiple mitosis were present in two cases (20/10 per high powered field; case numbers 6 and 9) (Table 2). The immunohistochemistry profiles are summarized in Table 3. Capsular invasion was present in three cases (case numbers 2, 6 and 9), spleen invasion was also present in case number 2 . Along with capsular invasion, mitosis, nuclear polymorphism and necrosis were also significant in case numbers 6 and 9 at the time of diagnosis. These two cases were considered as malignant SPN and treated with six courses of gemcitabine + cis-platinum chemotherapy. Multiple liver and omentum metastases developed in case number 2 at the seventh postoperative month; this patient died at the ninth month. Multiple liver and omentum metastases developed in case number 9 at the 20th postoperative month and she died at the 24th month. The other eight cases have been followed up closely for an average of 7.9 years (between 1 and 16 years) and no recurrence or metastasis has been seen.

\section{Discussion}

SPN is very rare; in fact, they only constitute about $5 \%$ of cystic pancreatic tumors and about 1 to $2 \%$ of exocrine pancreatic neoplasms [3]. They present mainly in the second and third decades of life [4]. Our series presented with a median age of 38.8 years, which is 
Table 1 Patients characteristics

\begin{tabular}{|c|c|c|c|c|c|c|c|c|c|c|}
\hline & Patient 1 & Patient 2 & Patient 3 & Patient 4 & Patient 5 & Patient 6 & Patient 7 & Patient 8 & Patient 9 & Patient 10 \\
\hline Age/Gender & $30 / F$ & 18/F & $21 / F$ & 18/F & $62 / F$ & $50 / F$ & $40 / F$ & $33 / F$ & $71 / \mathrm{F}$ & $45 / \mathrm{M}$ \\
\hline Operation & $\begin{array}{l}\text { Distal } \\
\text { pancreatectomy } \\
+ \text { splenectomy }\end{array}$ & $\begin{array}{l}\text { Distal } \\
\text { pancreatectomy } \\
\text { + splenectomy }\end{array}$ & Total mass exicion & $\begin{array}{l}\text { Spleen preser - } \\
\text { ving distal } \\
\text { pancrea -tectomy }\end{array}$ & $\begin{array}{l}\text { Distal } \\
\text { pancreatectomy } \\
+ \text { splenectomy }\end{array}$ & $\begin{array}{l}\text { Subtotal distal } \\
\text { pancreatectomy } \\
+ \text { splenectomy }\end{array}$ & $\begin{array}{l}\text { Total pancrea- } \\
\text { tectomy }\end{array}$ & $\begin{array}{l}\text { Distal } \\
\text { pancreatectomy } \\
+ \text { splenectomy }\end{array}$ & $\begin{array}{l}\text { Subtotal distal } \\
\text { pancreatectomy } \\
+ \text { splenectomy }\end{array}$ & $\begin{array}{l}\text { Spleen preser - } \\
\text { ving distal } \\
\text { pancrea -tectomy }\end{array}$ \\
\hline Tumor location & Body & Tail & Head & Tail & Tail & Body + Tail & Head + Body & Tail & Body + Tail & Tail \\
\hline Size(cm) & $9 \times 7 \times 5$ & $13 \times 9 \times 6.5$ & $13 \times 6 \times 5.5$ & $6.5 \times 5.7 \times 3.6$ & $4.5 \times 3.5 \times 3.2$ & $12.5 \times 11 \times 6$ & $4.3 \times 3 \times 3$ & $4 \times 3 \times 2$ & $11 \times 7 \times 7$ & $3 \times 3 \times 2$ \\
\hline İvasion & $(-)$ & Capsule and spleen & $(-)$ & $(-)$ & $(-)$ & Capsule & $(-)$ & $(-)$ & Capsule & $(-)$ \\
\hline Nodal status & $0 / 14$ & $0 / 10$ & $(-)$ & $(-)$ & $0 / 6$ & $0 / 14$ & $0 / 4$ & $0 / 7$ & 0/11 & $0 / 5$ \\
\hline Follow-up & Healthy & Healthy & Healthy & Healthy & Healthy & $\begin{array}{l}\text { 7th month Liver } \\
\text { and omental } \\
\text { Metastasis 9th } \\
\text { month exitus }\end{array}$ & $\begin{array}{l}\text { 29th day biliary } \\
\text { and pancrea-tic } \\
\text { fistula, } 41 \text { th } \\
\text { day exitus }\end{array}$ & Healthy & $\begin{array}{l}\text { 20th month Liver } \\
\text { and omental } \\
\text { Metastasis 24th } \\
\text { month exitus }\end{array}$ & Healthy \\
\hline
\end{tabular}




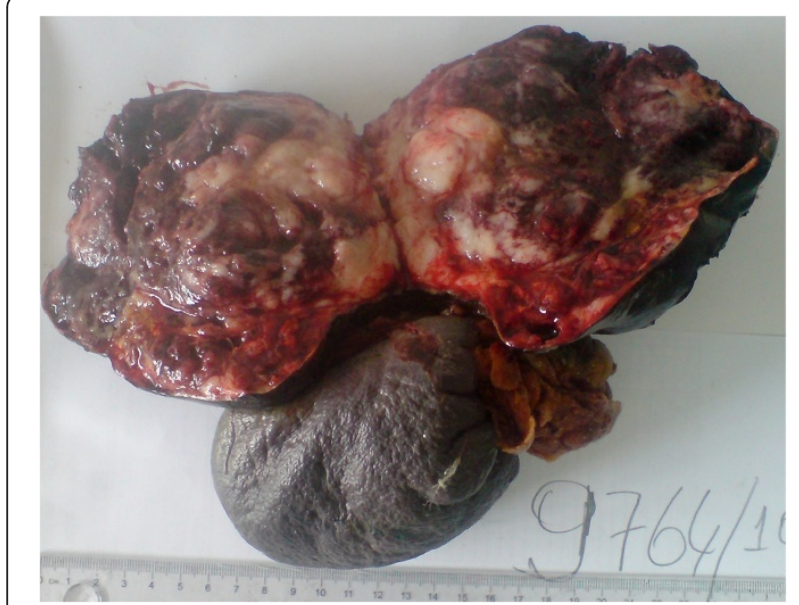

Figure 2 Macroscopic appearance of distal pancreatectomy + splenectomy specimen by SPN showing the solid and cystic component with hemorrhagic areas. SPN, solid pseudopapillary neoplasia.

significantly older than in the literature (median age of 26 years) $[5,6]$. The origin of solid pseudopapillary tumors still remains unclear. These neoplasms have been suggested to have a ductal epithelial, neuroendocrine, multipotent primordial cell, or even an extra-pancreatic genital ridge angle-related cell origin [7].

The clinical presentation of the tumor is usually nonspecific. Abdominal discomfort or vague pain is the most common symptom, followed by a gradually enlarging mass and compression signs induced by the tumor. Some patients are completely asymptomatic, with the tumor detected incidentally by imaging studies or routine physical examination. Usually there is no evidence of pancreatic insufficiency, abnormal liver function tests, cholestasis, elevated pancreatic enzymes or an endocrine syndrome. Tumor markers are also generally unremarkable $[4,8]$. In our series, seven patients $(70 \%)$ presented with abdominal pain or abdominal dullness, three patients (30\%) were asymptomatic with the diagnosis made by an incidental finding on routine examination and preoperative tumor markers (AFP, CEA, CA 19-9 and CA 125) were within normal limits in all patients.

SPN can occur in every part of the pancreas but they are slightly more common in the tail [3]. Grossly, it appears as a large and encapsulated mass, generally welldemarcated from the remaining pancreas. In fact, invasion of the adjacent organs, such as the spleen or the duodenal wall, is rare. Depending on the tumor position (head, body or tail of the pancreas), the differential diagnosis includes adrenal mass, pancreatic endocrine tumor, liver cyst or tumor, or a pseudocyst [9].

Abdominal ultrasound and CT show a well encapsulated, complex mass with both solid and cystic components and displacement of nearby structures. There may be calcifications at the periphery of the mass and intravenous contrast enhancement inside the mass suggesting hemorrhagic
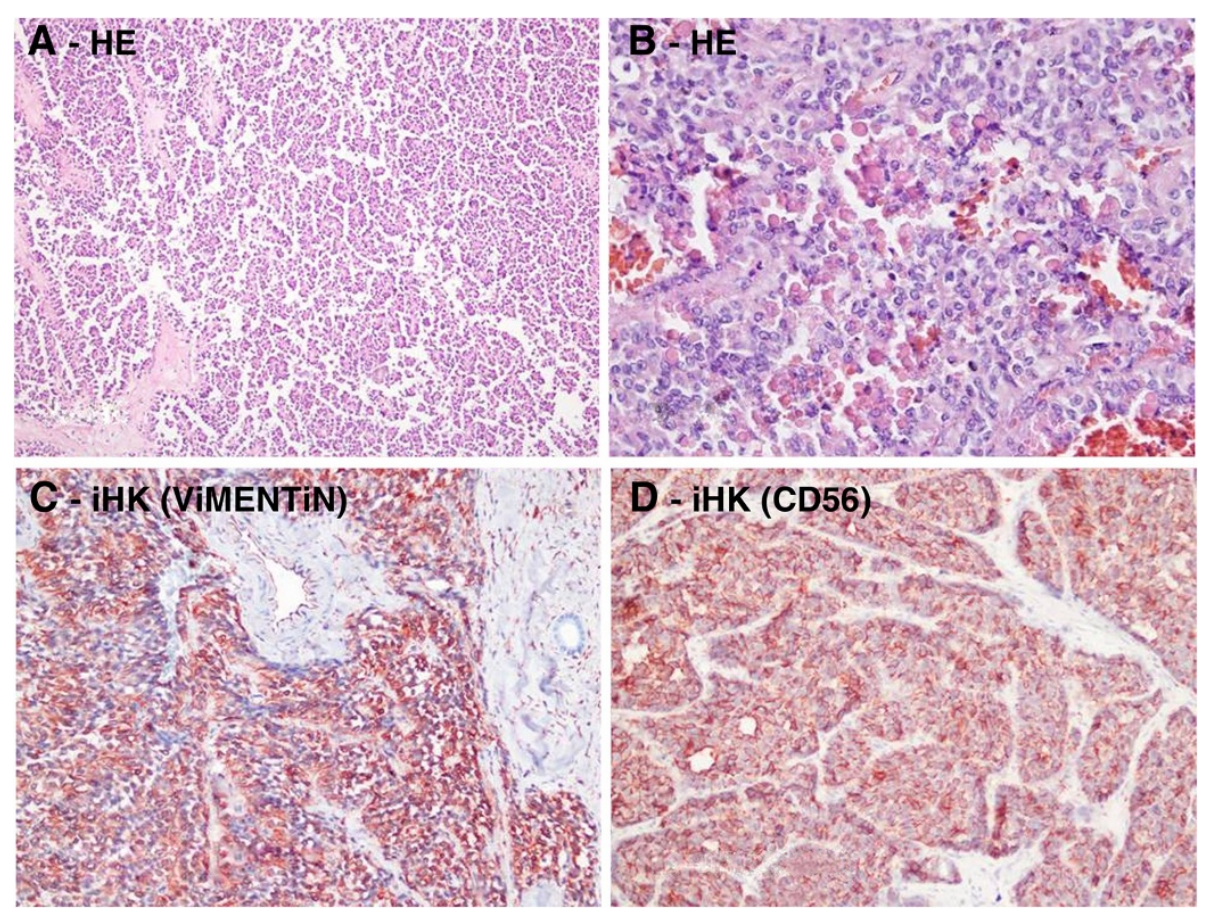

Figure 3 Histologic appearance of solid pseudopapillar tumors. (A) Solid pseudopapillar tumors exhibit a pseudopapillary pattern. (B) A portion of the tumor tissue shows a collection of hyaline globules. (C) Tumor cells typically show strong immunoreactivity for vimentin in the cytoplasm. (D) CD56 shows positive cytoplasmic membranous staining. 
Table 2 Histopathologic features

\begin{tabular}{|c|c|c|c|c|c|c|c|c|c|c|}
\hline & Patient 1 & Patient 2 & Patient 3 & Patient 4 & Patient 5 & Patient 6 & Patient 7 & Patient 8 & Patient 9 & Patient 10 \\
\hline $\begin{array}{l}\text { Development } \\
\text { pattern }\end{array}$ & $\begin{array}{l}\text { Solid, cystic, } \\
\text { papillary }\end{array}$ & $\begin{array}{l}\text { Cystic, } \\
\text { papillary }\end{array}$ & $\begin{array}{l}\text { Cystic, solid, } \\
\text { papillary }\end{array}$ & $\begin{array}{l}\text { Cystic, } \\
\text { papillary }\end{array}$ & $\begin{array}{l}\text { Cystic, solid, } \\
\text { papillary }\end{array}$ & $\begin{array}{l}\text { Solid, cystic, } \\
\text { papillary }\end{array}$ & $\begin{array}{l}\text { Solid, cystic, } \\
\text { papillary }\end{array}$ & $\begin{array}{l}\text { Solid, cystic, } \\
\text { papillary }\end{array}$ & $\begin{array}{l}\text { Solid, cystic, } \\
\text { papillary }\end{array}$ & $\begin{array}{l}\text { Cystic + } \\
\text { papillary }\end{array}$ \\
\hline Necrosis & $(-)$ & minimal & minimal & $(-)$ & $(-)$ & $(+)$ & $(-)$ & $(-)$ & $(+)$ & $(-)$ \\
\hline Mitosis & $(-)$ & $(-)$ & 2/10 per HPF & 2/10 per HPF & 2/10 per HPF & 20/10 per HPF & $(-)$ & $(-)$ & 20/10 per HPF & $(-)$ \\
\hline Pleomorphism & minimal & $(-)$ & minimal & minimal & minimal & manifest & minimal & $(-)$ & manifest & $(-)$ \\
\hline
\end{tabular}

necrosis [10]. However, when compared with MR imaging, CT has inherent limitations in showing certain tissue characteristics, such as hemorrhage, cystic degeneration, or the presence of a capsule. These features may, as shown at pathology, be suggestive of specific lesions such as SPN of the pancreas. Therefore, MR imaging may further aid in showing these characteristics and in the differential diagnosis of complex cystic masses within the pancreas [11]. Despite the technological improvements, preoperative diagnosis is difficult because of the similarity of findings among cystic lesions. Some studies advocate preoperative endosonography guided fine-needle aspiration biopsy for preoperative detection of the tumor, but this may not be accepted by others because of the uncertainty in diagnosis and the possible tumor spread $[12,13]$. In our series, preoperative endosonography guided fine-needle aspiration biopsy was performed in one out of ten patients and histology confirmed SPN.

In approximately $85 \%$ of the patients, SPN is limited to the pancreas, while about $10 \%$ to $15 \%$ of tumors have already metastasized at the time of presentation [14]. The most common sites for metastasis are the liver, regional lymph nodes, mesentery, omentum and peritoneum.

Once the diagnosis of SPN is made, surgery is the first choice of treatment. SPN is usually surrounded by a pseudocapsule and exhibits benign or low-grade malignancy. Conservative resection with preservation of as much pancreatic tissue as possible is the treatment of choice. According to the location of the tumor, distal pancreatectomy with or without splenectomy, pylorous preserving pancreatoduodenectomy, Whipple operation or enucleation can be performed. In our series, four patients underwent distal pancreatectomy with splenectomy, one patient underwent a total mass excision and one patient underwent total pancreatic resection. Two required extended distal pancreatectomy with splenectomy. Two underwent spleen-preserving distal pancreatectomy. Many studies have demonstrated that less aggressive surgical procedures could be preferred for the treatment of SPN [15]. Extensive lymphatic dissection or more radical approaches are not indicated when the disease is localized. Local invasion and metastases are not contraindications for resection. Portal vein resection is advocated when there is evidence of tumor invasion. For the metastases, surgical debulking should be performed, in contrast to other pancreatic malignancies. Metastases can be removed with enucleations or lobectomies and some patients with unresectable SPN may also have a long term survival [14]. The overall five-year survival rate of patients with SPN is about $95 \%$ [8].

Malignant SPN, designated as a solid-pseudopapillary carcinoma, occurs in $15 \%$ of adult patients. According to the WHO classification system, these are: 1) solidpseudopapillary neoplasms with borderline malignancy potential; and 2) solid-pseudopapillary carcinomas. Criteria which distinguish potentially malignant tumors and which are classified as 'SP carcinoma' are: 1)

Table 3 The immunohistochemistry study

\begin{tabular}{|c|c|c|c|c|c|c|c|c|c|c|}
\hline & Patient 1 & Patient 2 & Patient 3 & Patient 4 & Patient 5 & Patient 6 & Patient 7 & Patient 8 & Patient 9 & Patient 10 \\
\hline Cytokeratin & Focal $(+)$ & Focal $(+)$ & Focal $(+)$ & Focal $(+)$ & Focal $(+)$ & $(-)$ & Focal $(+)$ & $(-)$ & $(-)$ & $(-)$ \\
\hline CEA & $(-)$ & $(-)$ & $(-)$ & $(-)$ & $(-)$ & $(-)$ & $(-)$ & $(-)$ & $(-)$ & $(-)$ \\
\hline Vimentin & $(+)$ & $(+)$ & $(+)$ & $(+)$ & $(+)$ & Focal $(+)$ & $(+)$ & $(+)$ & $(+)$ & $(+)$ \\
\hline Chromogranin & $(-)$ & $(-)$ & $(-)$ & $(-)$ & Focal strong (+) & $(-)$ & $(-)$ & $(-)$ & $(-)$ & $(-)$ \\
\hline $\begin{array}{l}\text { Neuron specific } \\
\text { enolase }\end{array}$ & $(+)$ & $(+)$ & $(+)$ & Focal slight (+) & $(-)$ & $(+)$ & $(+)$ & $(+)$ & $(+)$ & $(+)$ \\
\hline CD10 & $(+)$ & Slight (+) & $(+)$ & $(+)$ & Focal $(+)$ & $(+)$ & $(+)$ & $(+)$ & $(+)$ & $(+)$ \\
\hline CD56 & Slight (+) & Slight (+) & $(+)$ & $(+)$ & $(-)$ & $(+)$ & $(+)$ & $(+)$ & $(+)$ & $(+)$ \\
\hline Synaptophysin & Focal $(+)$ & Focal $(+)$ & Focal $(+)$ & $(-)$ & $(+)$ & Slight focal (+) & Slight focal (+) & $(-)$ & $(-)$ & $(-)$ \\
\hline P53 & Focal slight (+) & $(-)$ & $(-)$ & $(-)$ & $(-)$ & $10 \%(+)$ & $5 \%(+)$ & $(-)$ & $10 \%(+)$ & $(-)$ \\
\hline Kí7 & $(-)$ & $(-)$ & $(-)$ & $(-)$ & Under $1 \%(+)$ & $10 \%(+)$ & $3 \%(+)$ & $(-)$ & $10 \%(+)$ & $(-)$ \\
\hline Progesterone & $(-)$ & $(+)$ & $(+)$ & $(-)$ & $(+)$ & $(-)$ & $(+)$ & $(+)$ & $(-)$ & $(+)$ \\
\hline EMA & Rare $(+)$ & Rare cells (+) & Rare cells (+) & Rare cells (+) & $(-)$ & Rare cells (+) & $(-)$ & $(-)$ & $(-)$ & $(-)$ \\
\hline
\end{tabular}


angioinvasion; 2) perineural invasion; and 3) deep invasion of the surrounding pancreatic parenchyma. A recent study showed that some histological features, such as extensive necrosis, nuclear atypia, high mitotic rate, immunohistochemistry findings of expression of Ki-67 and sarcomatoid areas may be associated with aggressive behavior [16].

Adjuvant therapy is used only in a small number of patients because of the high resectability of SPN. The role of chemotherapy or chemoradiotherapy in the treatment of SPN is also unclear. In some studies, adjuvant chemotherapy and radiotherapy are reported in some unresectable cases with good results $[17,18]$. Neoadjuvant chemotherapy or chemoradiotherapy is also reported to have been successful in a few cases [19-22].

In the light of previous studies, our two patients (patients number 6 and 9) had capsular invasion besides significant mitosis (20/10 per HPF), nuclear pleomorphism and necrosis at the time of diagnosis and Ki-67 index was $10 \%(+)$. These two patients were accepted as having malignant SPN. They were given gemcitabine + cis-platinum chemotherapy. Multiple liver and omentum metastases developed in case number 2 at the seventh postoperative month; she died at the ninth postoperative month. Multiple liver and omentum metastases developed in case number 9 at the 20th postoperative month and she died at the 24th postoperative month.

\section{Conclusions}

SPN is a rare neoplasm that primarily affects young women. The prognosis is favorable even in the presence of distant metastasis. Although surgical resection is generally curative, a close follow-up is advised in order to diagnose a local recurrence or distant metastasis and choose the proper therapeutic option for the patient.

\section{Abbreviations}

SPN: Solid pseudopapillary neoplasia; HPF: High-power fields; CT: Abdominal computed tomography; MRI: Magnetic resonance imaging.

\section{Competing interests}

The authors declare that they have no competing interests.

\section{Authors' contributions}

AY and SY participated in the data acquisition, data analysis, literature review and drafted the manuscript of this article. AC, NE and MY planned the analysis, participated in data acquisition, data analysis, literature review, patient treatment, and drafting and critical revision of the manuscript. EY and HP participated in immunohistochemisty and data analysis. All authors read and approved the final manuscript.

\section{Author details}

'Department of Pathology, M.D, SB Izmir Bozyaka Education and Research Hospital, Izmir, Turkey. ${ }^{2}$ Department of Surgery, M.D, SB Izmir Bozyaka Education and Research Hospital, Izmir, Turkey.

Received: 14 October 2013 Accepted: 22 November 2013 Published: 1 December 2013

\section{References}

1. Martin RC, Klimstra DS, Brennan MF, Conlon KC: Solid pseudopapillary tumor of the pancreas: a surgical enigma? Ann Surg Oncol 2002, 9:35-40.

2. Kloppel G, Solcia E, Longnecker DS, Capella C, Sobin LH: Histological typing of tumors of the exocrine pancreas. In [World Health Organization International Histological Classification of Tumours]. 2nd edition. Berlin, Heidelberg, New York: Springer; 1996:8452/1. ISBN [ISBN 3-540-60280-1].

3. Klimstra DS, Wenig BM, Heffess CS: Solid pseudopapillary tumor of the pancreas: a typically cystic carcinoma of low malignant potential. Semin Diagn Pathol 2000, 17:66-80.

4. Yu PF, Hu ZH, Wang XB, Guo JM, Cheng XD, Zhang YL, Xu Q: Solid pseudopapillary tumor of the pancreas: a review of 553 cases in Chinese literature. World J Gastroenterol 2010, 16:1209-1214.

5. Lam KY, Lo CY, Fan ST: Pancreatic solid-cystic-papillary tumor: clinico pathologic features in eight patients from Hong Kong and review of the literature. World J Surg 1999, 23:1045-1050.

6. Nishihara K, Nagoshi M, Tsuneyoshi M, Yamaguchi K, Hayashi I: Papillary cystic tumor of the pancreas. Assessment of their malignant potential. Cancer 1993, 71:82-92.

7. Eder F, Schulz HU, Röcken C, Lippert H: Solid-pseudopapillary tumor of the pancreatic tail. World J Gastroenterol 2005, 11:4117-4119.

8. Papavramidis T, Papavramidis S: Solid pseudopapillary tumors of the pancreas: review of 718 patients reported in English literature. J Am Coll Surg 2005, 200:965-972.

9. Canzonieri V, Berretta M, Buonadonna A, Libra M, Vasquez E, Barbagallo E, Bearz A, Berretta S: Solid pseudopapillary tumour of the pancreas. Lancet Oncol 2003, 4:255-256

10. Dong PR, Lu DS, Degregario F, Fell SC, Au A, Kadell BM: Solid and papillary neoplasm of the pancreas: Radiological-pathological study of five cases and review of the literature. Clin Radiol 1996, 51:702-705.

11. Cantisani V, Mortele KJ, Levy A, Glickman JN, Ricci P, Passariello R, Ros PR, Silverman SG: MR imaging features of solid pseudopapillary tumor of the pancreas in adult and pediatric patients. Am J Roentgenol 2003, 181:395-401.

12. Bardales RH, Centeno B, Mallery JS, Lai R, Pochapin M, Guiter G, Stanley MW: Endoscopic ultrasound-guided fine-needle aspiration cytology diagnosis of solid-pseudopapillary tumor of the pancreas: a rare neoplasm of elusive origin but characteristic cytomorphologic features. Am J Clin Pathol 2004, 121:654-662.

13. Raffel A, Cupisti K, Krausch M, Braunstein S, Trobs B, Goretzki PE, Willnow U: Therapeutic strategy of papillary cystic and solid neoplasm (PCSN): a rare non-endocrine tumor of pancreas in children. Surg Oncol 2004, 13:1-6.

14. Mao C, Guvendi M, Domenico DR, Kim K, Thomford NR, Howard JM: Papillary cystic and solid tumors of the pancreas: A pancreatic embryonic tumor? Studies of three cases and cumulative review of the world's literature. Surgery 1995, 118:821-828.

15. Zhang $H$, Liang TB, Wang $W L$, Shen $Y$, Ren GP, Zheng SS: Diagnosis and treatment of solid-pseudopapillary tumor of the pancreas. Hepatobiliary Pancreat Dis Int 2006, 5:454-458.

16. Tang LH, Aydin H, Brennan MF, Klimstra DS: Clinically aggressive solid pseudopapillary tumor of the pancreas. A report of two cases with components of undifferentiated carcinoma and a comparative clinicopathologic analysis of 34 conventional cases. Am J Surg Pathol 2005, 29:512-519.

17. Fried P, Cooper J, Balthazar E, Fazzini E, Newall J: A role for radiotherapy in the treatment of solid and papillary neoplasms of the pancreas. Cancer $1985,56: 2783-2785$.

18. Matsuda Y, Imai Y, Kawata S, Nishikawa M, Miyoshi S, Saito R, Minami $Y$, Tarui S: Papillary cystic neoplasm of the pancreas with multiple hepatic metastases: a case report. Gastroenterology Jpn 1987, 22:379-384.

19. Strauss JF, Hirsch VJ, Rubey CN, Pollock M: Resection of a solid and papillary epithelial neoplasm of the pancreas following treatment with cisplatinum and 5-fluorouracil: a case report. Med Pediatr Oncol 1993, 21:365-367.

20. Das G, Bhuyan C, Das BK, Sharma JD, Saikia BJ, Purkystha J: Spleen-preserving distal pancreatectomy following neoadjuvant chemotheraphy for papillary solid and cystic neoplasm of pancreas. Indian J Gastroenterol 2004, 23:188-189. 
21. Maffuz A, Bustamante FT, Silva JA, Torres-Vargas S: Preoperative gemcitabine for unresectable, solid pseudopapillary tumour of the pancreas. Lancet Oncol 2005, 6:185-186.

22. Zauls JA, Dragun AE, Sharma AK: Intensity-modulated radiation therapy for unresectable solid pseudopapillary tumor of the pancreas. Am J Clin Oncol 2006, 29:639-640.

doi:10.1186/1477-7819-11-308

Cite this article as: Yagcl et al:: Diagnosis and treatment of solid pseudopapillary tumor of the pancreas: experience of one single institution from Turkey. World Journal of Surgical Oncology 2013 11:308.

\section{Submit your next manuscript to BioMed Central} and take full advantage of:

- Convenient online submission

- Thorough peer review

- No space constraints or color figure charges

- Immediate publication on acceptance

- Inclusion in PubMed, CAS, Scopus and Google Scholar

- Research which is freely available for redistribution 